\title{
ANALISIS REGRESI DATA PANEL PADA INDEKS PEMBANGUNAN GENDER (IPG) JAWA TENGAH TAHUN 2011-2015*
}

\author{
Intan Lukiswati ${ }^{1}$, Anik Djuraidah ${ }^{2 \ddagger}$, and Utami Dyah Syafitri ${ }^{3}$ \\ 1Department of Statistics, IPB University, Indonesia, lukisintan@gmail.com \\ ${ }^{2}$ Department of Statistics, IPB University, Indonesia, anikdjuraidah@gmail.com \\ 32Department of Statistics, IPB University, Indonesia, utamids@apps.ipb.ac.id \\ ‡corresponding author
}

Indonesian Journal of Statistics and Its Applications (eISSN:2599-0802)

Vol 4 No 1 (2020), 89 - 96

Copyright (C) 2020 Intan Lukiswati, Anik Djuraidah, and Utami Dyah Syafitri. This is an open-access article distributed under the Creative Commons Attribution License, which permits unrestricted use, distribution, and reproduction in any medium, provided the original work is properly cited.

\begin{abstract}
The Gender Development Index (GDI) is a measure of the level of achievement of gender-based human development in Indonesia. Central Java Province is the largest province in Java with a GDI rate which tends to increase during the period of 2011 to 2015. Central Java's GDI, when compared to other provinces on Java Island, ranks third after DKI Jakarta and DI Yogyakarta. Central Java's GDI consists of several observations for a certain period of time so that panel data regression analysis can be used. The purpose of this study was to model the GDI of women in Central Java with panel data regression and find out which explanatory variables significantly affected women's GDI in Central Java from 2011 to 2015 . The results of this study indicate that explanatory variables that significantly influence women's GDI in Central Java are life expectancy, primary school enrollment rates, high school enrollment rates, and per capita expenditure.
\end{abstract}

Keywords: GDI, Jawa Tengah, panel data regression.

"Received Jun 2019; Accepted Feb 2020; Published online on Feb 2020 


\section{Pendahuluan}

Indeks Pembangunan Gender (IPG) merupakan suatu ukuran tingkat pencapaian pembangunan manusia berbasis gender di Indonesia. Komponen yang menyusun IPG terdiri dari dimensi umur panjang dan hidup sehat, dimensi pengetahuan, dan dimensi standar hidup layak. IPG diperoleh dari hasil rasio antara IPM penduduk perempuan dengan penduduk laki-laki. Jika nilai IPG kurang dari 100 maka terdapat ketimpangan gender dalam pembangunan manusia.

Masalah ketimpangan gender di Indonesia saat ini masih terjadi dalam pelaksanaan pembangunan manusia. Kesenjangan tersebut terlihat pada beberapa aspek salah satunya aspek kesempatan kerja dan ekonomi. Data Bappenas tahun 2015 menunjukkan bahwa Indonesia termasuk satu dari tiga negara ASEAN dengan Indeks Pembangunan Gender (IPG) yang rendah.

Provinsi Jawa Tengah merupakan provinsi terbesar di Pulau Jawa dengan angka IPG yang cenderung terjadi peningkatan selama kurun waktu 2011 hingga 2015. Pada tahun 2011 IPG Jawa Tengah mencapai 90.92 kemudian naik menjadi 92.91 pada tahun 2015. IPG Jawa Tengah jika dibandingkan dengan beberapa provinsi lain di pulau jawa menduduki urutan ketiga setelah DKI Jakarta dan DI Yogyakarta. Beberapa penelitian telah dilakukan di Indonesia untuk mengetahui faktor-faktor yang mempengaruhi IPG antara lain penelitian yang dilakukan oleh Fitarisca (2014) serta Fajriyyah (2015). IPG Jawa Tengah terdiri dari beberapa amatan pada periode waktu tertentu sehingga dapat digunakan analisis regresi data panel.

Data panel merupakan gabungan dari data cross section dan time series. Menurut Gujarati (2004) data panel adalah data cross section yang diamati dalam beberapa periode waktu. Menurut Baltagi (2005) data panel memiliki beberapa kelebihan dibandingkan data cross section salah satunya adalah data panel dapat menyajikan informasi lebih lengkap dan meningkatkan presisi. Hsiao (2014) mengemukakan bahwa keuntungan dari data panel adalah parameter model yang diperoleh lebih akurat dan peneliti dapat menganalisis masalah yang tidak dapat dipecahkan dengan data cross section atau data yang hanya mengandung unsur waktu. Penelitian terkait regresi data panel tentang pembangunan manusia antara lain dilakukan oleh Arifiana (2017), Ramadhan (2018), dan Rizki et al. (2015).

Tujuan penelitian ini adalah untuk memodelkan IPG perempuan di Jawa Tengah dengan regresi data panel dan mengetahui peubah penjelas apa saja yang nyata berpengaruh terhadap IPG perempuan di Jawa Tengah tahun 2011 hingga 2015.

\section{Metodologi}

\subsection{Bahan dan Data}

Data yang digunakan dalam penelitian ini adalah data sekunder yang bersumber dari Badan Pusat Statistik (BPS, 2014) yaitu data IPG sebagai peubah respon dan sebanyak tujuh peubah penjelas. Pemilihan peubah penjelas didasarkan pada penelitian-penelitian yang telah dilakukan sebelumnya yaitu peubah-peubah penjelas yang berpengaruh terhadap nilai IPG. Dalam penelitian ini hanya membatasi untuk penduduk berjenis kelamin perempuan. Cakupan penelitian ini adalah kabupaten/kota 
di Jawa Tengah tahun 2011 sampai dengan 2015. Peubah-peubah yang digunakan dalam penelitian ini disajikan pada Tabel 1 .

Tabel 1: Peubah-peubah yang digunakan dalam penelitian.

\begin{tabular}{|c|c|c|}
\hline Peubah & Satuan & Sumber Pustaka \\
\hline Indeks Pembangunan Gender (Y) & & 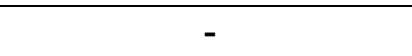 \\
\hline Angka Harapan Hidup (X1) & Tahun & (KEMENPPPA, 2013) \\
\hline $\begin{array}{l}\text { Persentase penduduk mengalami keluhan } \\
\text { kesehatan (X2) }\end{array}$ & Persen & (Fajriyyah, 2015) \\
\hline $\begin{array}{l}\text { Angka Partisipasi Sekolah SD/sederajat } \\
\text { (X3) }\end{array}$ & Persen & (Fajriyyah, 2015) \\
\hline $\begin{array}{l}\text { Angka Partisipasi Sekolah SMP/sederajat } \\
\text { (X4) }\end{array}$ & Persen & (Fajriyyah, 2015) \\
\hline $\begin{array}{l}\text { Angka Partisipasi Sekolah SMA/sederajat } \\
\text { (X5) }\end{array}$ & Persen & (Fitarisca, 2014) \\
\hline Pengeluaran per kapita (X6) & Rupiah & (Fitarisca, 2014) \\
\hline Tingkat Partisipasi Angkatan Kerja (X7) & Persen & (Fajriyyah, 2015) \\
\hline
\end{tabular}

\subsection{Metode Penelitian}

Langkah-langkah analisis data yang dilakukan dalam penelitian ini adalah sebagai berikut :

a. Melakukan pengumpulan data dari berbagai sumber.

b. Melakukan eksplorasi data IPG secara deskriptif.

c. Melakukan pengujian multikolinearitas antar peubah-peubah penjelas.

d. Menentukan model terbaik data panel melalui uji Chow dan uji Haussman.

i. Uji Chow

Uji Chow digunakan untuk menguji antara model common effect model dan model pengaruh tetap (Baltagi, 2005). Hipotesisnya sebagai berikut:

$H_{0}: \mu_{1}=\mu_{2}=\cdots=\mu_{n-1}=0$ (model pengaruh umum)

$H_{1}$ : minimal terdapat satu $\mu_{i} \neq 0$ (model pengaruh tetap)

Statistik uji:

$$
F_{h i t}=\frac{(R R S S-U R S S) /(n-1)}{U R S S /(n t-n-p)}
$$

dengan:

$R R S S$ = jumlah kuadrat sisaan terbatas dari model pengaruh umum.

$U R S S=$ jumlah kuadrat sisaan tidak terbatas dari model pengaruh tetap.

nt = banyaknya amatan tiap waktu.

$p \quad=$ banyaknya parameter.

Kriteria penolakan $H_{0}$ : jika $F_{h i t}>F_{(n-1, n t-n-p)}$

ii. Uji Hausman

Uji Hausman digunakan untuk menguji antara model pengaruh acak dengan model pengaruh tetap (Baltagi, 2005). Hipotesisnya sebagai berikut:

$H_{0}: E\left(\delta_{i t} \mid X_{i t}\right)=0$ (model pengaruh acak)

$H_{1}: E\left(\delta_{i t} \mid X_{i t}\right) \neq 0$ (model pengaruh tetap) 
Statistik uji:

dengan:

$$
\chi_{\text {hit }}^{2}=(\boldsymbol{b}-\boldsymbol{\beta})^{T} \operatorname{Var}(\boldsymbol{b}-\boldsymbol{\beta})^{-1}(\boldsymbol{b}-\boldsymbol{\beta})
$$

$\boldsymbol{b}=$ vektor estimasi parameter model pengaruh tetap.

$\boldsymbol{\beta}=$ vektor estimasi parameter model pengaruh acak.

Kriteria penolakan $H_{0}$ : jika $\chi_{\text {hit }}^{2}>\chi_{p}^{2}$

e. Melakukan interpretasi hasil.

\section{Hasil dan Pembahasan}

\subsection{Gambaran Umum Data IPG}

Provinsi Jawa Tengah memiliki 35 kabupaten/kota yang terdiri dari 29 kabupaten dan 6 kota. Nilai IPG kabupaten/kota di Jawa Tengah dapat dipetakan pada Gambar 1. Gambar tersebut menunjukkan bahwa nilai sebaran IPG bervariasi selama tahun 2011 hingga 2015. Pada beberapa kabupaten/kota yang letaknya berdekatan cenderung membentuk suatu kelompok. Dalam gambar tersebut dapat dijelaskan bahwa IPG kabupaten/kota yang terletak di sebelah barat selama 2011 hingga 2013 cenderung konstan yaitu berada pada selang IPG antara 83 dan 86 . Kabupaten/kota tersebut antara lain Cilacap, Brebes, Tegal, dan Kota Tegal. Kemudian pada tahun 2014 dan 2015 mengalami peningkatan menjadi selang IPG antara 86 dan 89 kecuali Kabupaten Brebes. Kabupaten/kota yang terletak di tengah cenderung terus mengalami peningkatan dari tahun ke tahun menuju IPG yang tinggi yakni lebih besar dari 92. Kabupaten/kota yang termasuk di dalamnya antara lain Banjarnegara, Kebumen, Purworejo, Wonosobo, Magelang, Kota Magelang, Kota Salatiga, Kota Semarang, dan 11 kabupaten/kota lainnya. Pada tahun 2011 hingga 2014 Kota Surakarta menjadi kota dengan IPG tertinggi di Jawa Tengah. Kemudian di tahun 2015 digantikan oleh Kabupaten Sukoharjo, sedangkan Kota Surakarta menduduki peringkat ketiga. Beberapa kabupaten/kota yang terletak di sebelah timur juga cenderung mengalami peningkatan dari tahun ke tahun walaupun peningkatannya tidak secepat kabupaten/kota yang terletak di tengah provinsi Jawa Tengah.

Kabupaten Pati, Kudus, Jepara, dan Demak mengalami peningkatan IPG dari yang semula berada pada selang antara 86 dan 89 menjadi selang antara 89 dan 92 selama tahun 2011 hingga 2015. IPG Kabupaten Grobogan selama tahun 2011 sampai 2015 tidak mengalami perubahan yakni terletak pada selang antara 83 dan 86 . Selama tahun 2011 hingga 2014 Kabupaten Blora menjadi kabupaten dengan IPG terendah di Jawa Tengah kemudian mengalami peningkatan pada tahun 2015. 

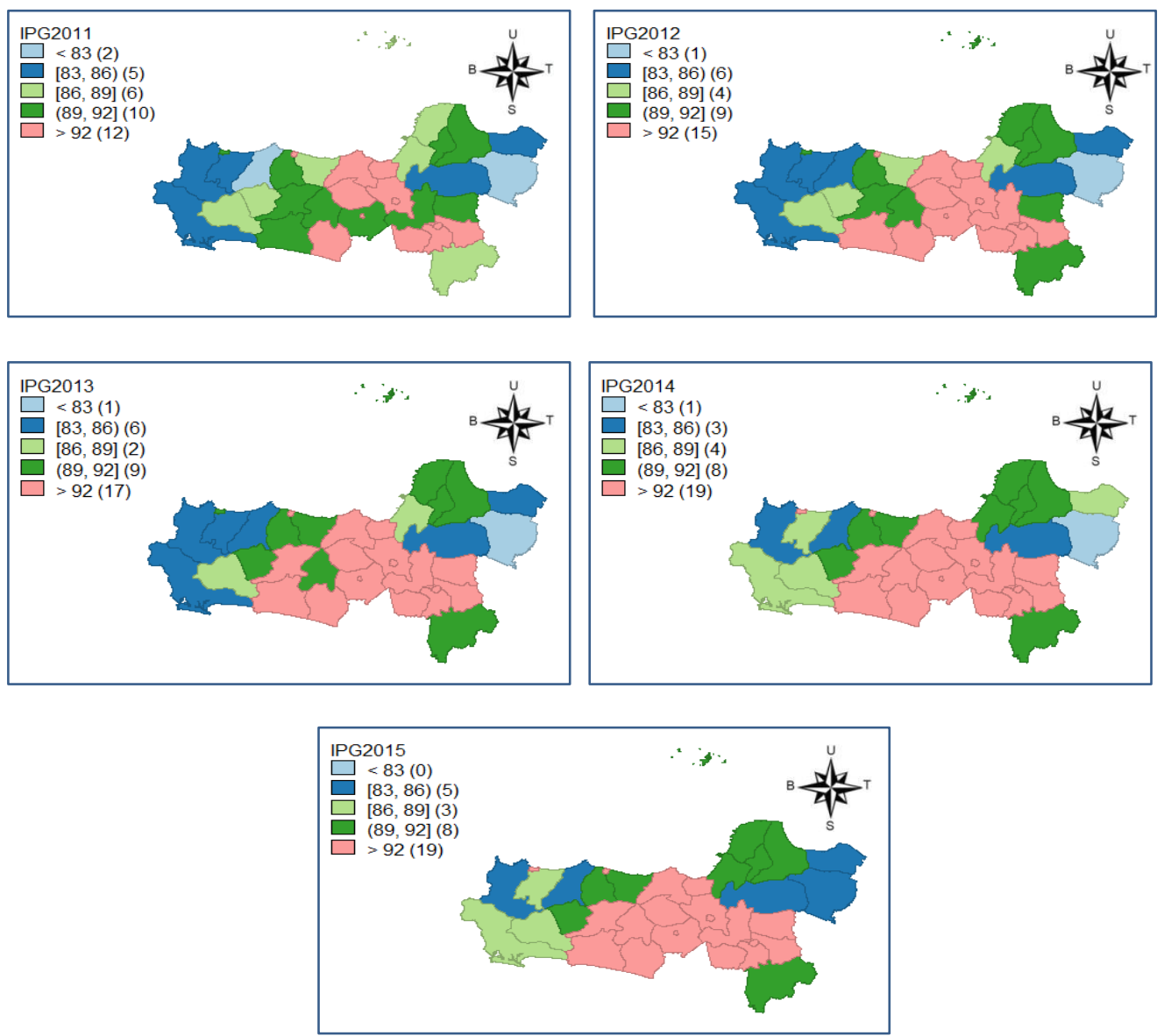

Gambar 1: Peta Sebaran IPG kabupaten/kota di Jawa Tengah Tahun 2011-2015 (Peta tidak memiliki skala).

Keeratan hubungan yang bersifat linier antar peubah tahun 2011 sampai dengan 2015 secara gabungan dapat dijelaskan dalam Tabel 2. Pada tabel tersebut terlihat bahwa peubah penjelas yang memiliki nilai koefisien korelasi cukup tinggi dengan peubah responnya antara lain peubah angka harapan hidup (X1) dan pengeluaran per kapita (X6). Peubah penjelas yang lain nilai koefisien korelasinya tidak terlalu tinggi dengan peubah responnya (IPG) namun cukup signifikan/nyata. Hal tersebut ditunjukkan oleh nilai nilai-p pada seluruh peubah penjelas yang kurang dari $5 \%(0.05)$ sehingga dapat dikatakan memiliki hubungan linier dengan peubah responnya. Berdasarkan Tabel 2 tersebut juga terlihat bahwa hampir semua peubah penjelas memiliki hubungan yang positif dengan peubah responnya kecuali peubah persentase penduduk perempuan yang mengalami keluhan kesehatan yang memiliki hubungan negatif dengan peubah responnya. Penelitian ini menggunakan seluruh peubah penjelas dalam analisis karena seluruh peubah penjelas terbukti secara nyata memiliki hubungan linier dengan IPG (Y). 
Tabel 2: Koefisien korelasi antar peubah.

\begin{tabular}{lrrrrrrr}
\hline & Y & X1 & X2 & X3 & X4 & X5 & X6 \\
\hline X1 & 0.60 & & & & & & \\
Nilai-p & $(0.00)$ & & & & & & \\
X2 & -0.16 & -0.30 & & & & & \\
Nilai-p & $(0.04)$ & $(0.00)$ & & & & & \\
X3 & 0.31 & 0.17 & -0.07 & & & & \\
Nilai-p & $(0.00)$ & $(0.02)$ & $(0.38)$ & & & & \\
X4 & 0.26 & 0.47 & 0.03 & 0.20 & & & \\
Nilai-p & $(0.00)$ & $(0.00)$ & $(0.69)$ & $(0.01)$ & & & \\
X5 & 0.42 & 0.44 & 0.08 & 0.24 & 0.60 & & \\
Nilai-p & $(0.00)$ & $(0.00)$ & $(0.30)$ & $(0.00)$ & $(0.00)$ & & \\
X6 & 0.81 & 0.64 & 0.08 & 0.20 & 0.38 & 0.54 & \\
Nilai-p & $(0.00)$ & $(0.00)$ & $(0.29)$ & $(0.01)$ & $(0.00)$ & $(0.00)$ & \\
X7 & 0.35 & 0.36 & -0.19 & 0.15 & 0.06 & -0.08 & 0.20 \\
Nilai-p & $(0.00)$ & $(0.00)$ & $(0.01)$ & $(0.05)$ & $(0.46)$ & $(0.32)$ & $(0.01)$ \\
\hline
\end{tabular}

\subsection{Pengujian Multikolinearitas pada Data IPG}

Pemeriksaan multikolinearitas antar peubah penjelas dapat dilakukan dengan melihat nilai VIF (Variance Inflation Factor). Multikolinearitas antar peubah penjelas berpengaruh besar jika nilai VIF yang diperoleh lebih besar dari sepuluh (VIF > 10). Tabel 3 menjelaskan tentang multikolinearitas berdasarkan nilai VIF setiap peubah penjelasnya. Berdasarkan Tabel 3 dapat dilihat bahwa pada tahun 2011 sampai 2015 nilai VIF seluruh peubah penjelas lebih kecil dari sepuluh sehingga tidak terjadi multikolinearitas. Nilai VIF pada data gabungan tahun 2011 hingga 2015 menunjukkan pada seluruh peubah penjelas kurang dari 10 sehingga tidak terjadi multikolinearitas. Dengan demikian dalam penelitian ini seluruh peubah penjelas dapat digunakan dalam pemodelan data panel.

Tabel 3: Nilai VIF setiap peubah penjelas.

\begin{tabular}{cccccccc}
\hline Peubah & X1 & X2 & X3 & X4 & X5 & X6 & X7 \\
\hline 2011 & 2.84 & 1.32 & 1.13 & 2.23 & 2.45 & 2.42 & 1.33 \\
2012 & 3.05 & 1.58 & 1.26 & 1.62 & 1.69 & 2.70 & 1.33 \\
2013 & 2.92 & 1.45 & 1.90 & 1.86 & 1.61 & 2.55 & 1.73 \\
2014 & 3.53 & 1.48 & 1.41 & 1.97 & 1.87 & 2.66 & 1.44 \\
2015 & 2.77 & 1.16 & 1.26 & 2.05 & 2.07 & 2.27 & 2.11 \\
$2011-2015$ & 2.68 & 1.34 & 1.11 & 1.74 & 2.05 & 2.26 & 1.28 \\
\hline
\end{tabular}

\subsection{Model Regresi Data Panel}

Pemilihan model terbaik data panel dapat dilakukan melalui uji Langrange Multiplier (LM), uji Chow, dan uji Haussman. Berdasarkan Tabel 4 dapat terlihat bahwa nilai-p pada uji LM lebih kecil dari taraf nyata $5 \%$ sehingga dapat disimpulkan bahwa model 
yang dipilih data panel dengan pengaruh acak. Hasil uji Chow menunjukkan bahwa nilai-p lebih kecil dari taraf nyata $5 \%$ sehingga disimpulkan bahwa model yang terpilih adalah model data panel pengaruh tetap. Sedangkan uji Haussman menunjukkan nilai-p juga lebih kecil dari taraf nyata $5 \%$ sehingga disimpulkan bahwa model data panel terpilih adalah model dengan pengaruh tetap. Dari penjelasan tersebut dapat disimpulkan bahwa model data panel yang tepat digunakan adalah data panel dengan pengaruh tetap.

Tabel 4: Hasil uji LM, Chow dan Haussman.

\begin{tabular}{cccc}
\hline Uji & LM & Chow & Haussman \\
\hline Nilai statistik & 14.61 & 122.59 & 21.06 \\
Nilai-p & $<2.2 \mathrm{e}-16$ & $<2.2 \mathrm{e}-16$ & 0.004 \\
\hline
\end{tabular}

\subsection{Interpretasi Model Regresi Data Panel}

Tabel 5 menampilkan hasil pendugaan parameter model regresi data panel pengaruh tetap dengan tujuh peubah penjelas dengan peubah IPG. Peubah yang nyata pada taraf nyata 5\% adalah APS SD/sederajat dan APS SMA/sederajat. Peubah angka harapan hidup nyata pada taraf nyata $1 \%$, sedangkan pengeluaran per kapita nyata pada taraf nyata $0.1 \%$. Hal tersebut menjelaskan bahwa keempat peubah penjelas tersebut secara nyata memiliki pengaruh yang positif terhadap IPG penduduk perempuan. Nilai koefisien determinasi $\left(R^{2}\right)$ yang dihasilkan dari model tersebut sebesar $78.94 \%$, sedangkan $\mathrm{R}^{2}$ terkoreksi sebesar $72.45 \%$. Nilai $\mathrm{R}^{2}$ tersebut termasuk cukup tinggi sehingga dapat dikatakan bahwa regresi data panel dengan pengaruh tetap cukup baik untuk memodelkan data IPG penduduk perempuan Jawa Tengah tahun 2011 hingga 2015.

Berdasarkan hasil pendugaan parameter model regresi data panel pada Tabel 5, maka dapat dituliskan persamaan model data panel sebagai berikut:

$$
\begin{gathered}
y_{i t}=1.1303 X_{1 i t}+0.0033 X_{2 i t}+0.1028 X_{3 i t}+0.0044 X_{4 i t}+0.01 X_{5 i t}+0.001 X_{6 i t} \\
-0.002 X_{7 i t}
\end{gathered}
$$

Tabel 5: Pendugaan parameter regresi data panel dengan pengaruh tetap.

\begin{tabular}{lcccc}
\hline Peubah & Koefisien & Galat baku & t-statistik & Nilai-p \\
\hline AHH (X1) & 1.1303 & 0.4225 & 2.6756 & $0.0084^{* *}$ \\
Penduduk mengeluh sakit (X2) & 0.0033 & 0.0099 & 0.3357 & 0.7376 \\
APS SD (X3) & 0.1028 & 0.0466 & 2.2069 & 0.0290 \\
APS SMP (X4) & 0.0044 & 0.0107 & 0.4110 & 0.6817 \\
APS SMA (X5) & 0.0100 & 0.0047 & 2.1362 & $0.0345{ }^{*}$ \\
Pengeluaran perkapita (X6) & 0.0010 & 0.0001 & 10.1591 & $0.0000^{* *}$ \\
TPAK (X7) & -0.0020 & 0.0100 & -0.1971 & 0.8441 \\
\hline
\end{tabular}

\footnotetext{
$\left.{ }^{*}\right)$ nyata pada $\left.\alpha=5 \%,{ }^{, *}\right)$ nyata pada $\left.\alpha=1 \%,{ }^{* \star *}\right)$ nyata pada $\alpha=0.1 \%$
} 


\section{Simpulan}

Model regresi data panel pada data IPG perempuan di Jawa Tengah tahun 2011 hingga 2015 cukup baik yang ditunjukkan dengan nilai koefisien determinasi cukup tinggi yaitu sebesar $78.94 \%$. Peubah-peubah penjelas yang nyata berpengaruh terhadap data IPG perempuan di Jawa Tengah antara lain angka harapan hidup, angka partisipasi sekolah SD/sederajat, angka partisipasi sekolah SMA/sederajat, dan pengeluaran per kapita.

Hasil koefisien determinasi yang dihasilkan dari model regresi data panel sudah cukup baik, namun penulis masih mengharapkan pada penelitian selanjutnya dapat ditambahkan peubah-peubah yang lain dalam model agar dapat lebih meningkatkan presisinya.

\section{Daftar Pustaka}

Arifiana, A. R. (2017). Faktor-Faktor yang Memengaruhi Indeks Pembangunan Manusia di Provinsi Jawa Tengah Periode 2010-2014 [Skripsi]. Bogor (ID): Institut Pertanian Bogor.

Baltagi, B. H. (2005). Econometrics Analysis of Panel Data [3rd ed.]. England (GB): John Wiley and Sons.

[BPS] Badan Pusat Statistik. (2014). Indeks Pembangunan Gender 2014. Jakarta (ID): Badan Pusat Statistik.

Fajriyyah, N. (2015). Pemodelan Indeks Pembangunan Gender dengan Pendekatan Regresi Nonparametrik Spline di Indonesia [skripsi]. Surabaya (ID): Institut Teknologi Sepuluh Nopember.

Fitarisca, A. (2014). Analisis Faktor-Faktor yang Mempengaruhi Indeks Pembangunan Gender (IPG) dengan Menggunakan Regresi Probit [skripsi]. Surabaya (ID): Institut Teknologi Sepuluh Nopember.

Gujarati, D. (2004). Applied Econometrics. Singapore (SG): Mc. Graw-Hill International Editions.

Hsiao, C. (2014). Analysis of panel data. California (US): Cambridge university press.

[KEMENPPPA] Kementrian Pemberdayaan Perempuan dan Perlindungan Anak. (2013). Pembangunan Manusia Berbasis Gender 2013. Jakarta (ID): Kementrian Pemberdayaan Perempuan dan Perlindungan Anak.

Ramadhan, A. F. (2018). Analisis Regresi Data Panel untuk Pemodelan Indeks Pembangunan Manusia di Jawa Tengah [Skripsi]. Bogor (ID): Institut Pertanian Bogor.

Rizki, M., Rusgiyono, A., \& Mukid, M. A. (2015). Pemodelan Indeks Pembangunan Manusia di Provinsi Jawa Tengan Tahun 2008-2013 dengan Menggunakan Regresi Data Panel. Jurnal Gaussian, 4(2): 345-354. 